\title{
Attitudinal and Behavioural Determinants Influencing Decision Makers When Adopting Integration Technologies in Local Government
}

\author{
Muhammad Kamal \\ Business School \\ Brunel University \\ Muhammad.kamal@brunel.ac.uk
}

\author{
Vishanth Weerakkody \\ Business School \\ Brunel University \\ Vishanth.weerakkody@brunel.ac.uk
}

\author{
Zahir Irani \\ Business School \\ Brunel University \\ Zahir.irani@brunel.ac.uk
}

\begin{abstract}
Over the last few years, the advent of innovative or revolutionary integration technologies has influenced pivotal decisions within top management to strategically transform Local Government Authorities (LGAs). These technologies may represent a huge cost for adopting LGAs, but may also offer the chance to achieve competitive advantage through superior service delivery. With the emergence of electronic Government (eGovernment), LGAs are turning to integration technologies to fully automate and e-enable their business processes and integrate their IT infrastructures. While prior research on the adoption of integration technologies in the private and public domain has considered several determinants (e.g. benefits, barriers, costs), little attention has been given to investigate the attitudinal and behavioural determinants influencing top management's decision making process for the adoption of integration technologies in LGAs. Notwithstanding, the implications of this research have yet to be assessed, leaving scope for timeliness and novel research. Therefore, it is of high importance to investigate this area within LGAs and contribute to the area of strategic decision making by examining attitudinal and behavioural determinants of top management in relation to integration technologies adoption.
\end{abstract}

\section{Introduction}

While the 1990s saw the internet-enabled electronic Commerce (e-Commerce) revolution with private and multinational organisations, in the new millennium we have witnessed public sector organisations embracing the same principles of electronic Business (e-Business) by e-enabling central and LGA services through the introduction of e-Government initiatives. The concept e-Government was first introduces in the United Kingdom (UK) in 1999 by the Labour government led by Tony Blair.
The national strategy for e-enabling public services, including all LGAs was published in November 2002 and outlined a highly ambitious program of transformation in the public sector. In brief, the national e-Government strategy was to be delivered by a newly formed office of the 'e-envoy' and the government's commitment to delivering 100 percent of public services online by 2008 was the key to the UK's e-Government program. This target of 2008 was subsequently revised to 2005 and again changed back to 2008 by the Deputy Prime Ministers (ODPM) office to assist any local authorities that were lagging in their implementation efforts [18].

To reach the e-Government vision in the UK, the government set out a cohesive strategy with a clearly articulated action plan that leverages the resources of the private sector. This is backed by a strong leadership structure at central government level. The national strategy aimed at creating a common framework where local strategies can be planned with confidence. The framework also described what needed to be put in place nationally to help this happen. Common priorities for developments in technology and 'joined up' services that would reduce the costs of LGAs were also identified [55]. In transforming services, LGAs were to be e-Business oriented, more accessible, convenient, responsive and cost-effective [54]. Consequently, the UK initiated broad changes to its e-Government program in 2004. Along with significant increases in expenditure on Information Technology (IT) and progress on a number of high profile programs, a new vision for Information and Communication Technology (ICT) has been developed, spearheaded through the reformation of the office of the e-envoy into the eGovernment Unit (e-GU). According to Accenture [1], the new role of the e-GU was focused on ensuring that IT supports the business transformation of government itself so that it can provide better, more efficient public services. Each government agency and LGA is responsible to define its own IT strategy that will join up with other services to support the e-GU's plans [1].

The UK government has four guiding principles for its e-Government strategy: building services 
around the citizens needs; making government and services more accessible; social inclusion; and making better use of information [56]. The UK has always been conscious that e-Government is a means to help drive the local policy objectives of mainstream services, release efficiency gains and achieve tangible improvements in terms of shared priorities agreed between central and LGAs $[34,56$, 74]. It is important to note that although the overall egovernment strategy is common for the whole of United Kingdom; local e-Government focus varies between different regions in the UK due to differences in political and historical contexts. For instance, Wales is different to that of the rest of the UK. In Wales, the targets were less ambitious, with the Welsh Assembly Government stating that the public sector had to develop Implementing Electronic Government Statements, which set out each Authority's vision by July 2003. The Welsh Assembly did not require Welsh Councils to implement all services online by 2005 , as was the situation in the rest of the UK. Rather, the Assembly required Councils to develop eGovernment services based on local context and citizen needs [52]. When LGAs are faced with the prospect of transformational change because of the implementation of e-Government, then the resulting organisational change is heavily dependent on the decisions taken by top management to make the transition from a largely traditional, pre-ICT era, to new means of administering in a new and evolving environment. This means that public sector organisations that are renowned for being outdated, bureaucratic, and slow to change have to transform to an open, transparent and rapidly changing environment $[34 ; 73 ; 74]$.

It is outside the scope of this paper to investigate to what extent the UK plans for implementing eGovernment have been accomplished at LGA level. However, current research suggests that there has been mixed success and not all LGAs have achieved the target [65]. Irrespective of these different levels of success however, in order to find good practice in implementation of local e-Government it is important to look at LGAs in different regions and examine their strategies and solutions to identify what is working and what is not particularly in terms of adoption of technology adoption. While prior information systems research in the private and public domain has considered several determinants (e.g. benefits, barriers, costs), little attention has been given to investigate the attitudinal and behavioural determinants influencing top management's decision making process for technology adoption and integration in LGAs. Herein lies the rationale and motivations for this research. This research is particularly relevant for LGAs who are lagging behind in the wider national context regarding meeting the deadlines for e-Government implementation in the UK. Using this reasoning, this paper will examine two UK LGAs with a view of identifying the attitudinal and behavioural determinants influencing the strategic decision making processes in top management. The basis for selecting LGAs from two different regions, England and Wales, was influenced by the fact that these two regions have different governing structures and operational practices within their LGAs [10]. Furthermore, the complexity of IT implementations, level of integration achieved and management outlook on e-government varied much between the two LGAs making them an ideal proposition for further study. Given this background, from a methodological stance a multiple-case-study based approach was deemed suitable for the research. .

To determine the question established above, this paper is divided as follows. In the next section the authors present a literature perspective on eGovernment. Thereafter, the following sections represent the national and local e-Government strategy in the context of UK. Then the authors discuss on the IT adoption stance in LGAs and thereafter highlighting the limitations. This is followed by developing a conceptual stance for this research, in doing so the authors discuss on the attitudinal and behavioural determinants influencing the decision making process. The next section presents the research methodology utilised to test the research issues highlighted in previous section. The case study findings are analysed next followed by the final summary and conclusions.

\section{A Theoretical Perspective on E- Government}

Advancements in innovative IT solutions has enabled not only the private sector, but also public institutions to radically improve the way they perform their operational activities. This has enabled particularly LGAs to transform the way services are offered to citizens $[30,24]$. With the help of big IT companies and vendors, LGAs are realising that by exploiting the similar principles and technologies that are fuelling e-Business development, they can also achieve such similar revolution - the result of this rejuvenation has contributed to the advent of eGovernment [73]. E-Government has been defined using various perspectives. Principally in the context of this research, e-Government broadly refers to the strategic application of IT to facilitate and transform the government $[16,59]$. This involves the strategic use of IT to provide citizens and organisations with better information and services delivery, and for governments to interact with business partners and 
transact internally at local, municipal, state and national levels [30, 38]. Silcock [64] supports that eGovernment has the power to create a new strategic approach of public service where all the LGAs deliver a modernised, integrated and seamless service for their citizens and other stakeholders. Several researchers support this argument and state that there is little doubt about the effectiveness and potential of e-Government, as over the past few years many countries have started developing e-Government infrastructures [43].

The drivers for e-Government essentially include among others: improving internal cost and management efficiencies, encouraging citizen participation, promoting economic development and improving overall governance $[73,46]$. While the eGovernment terminology only transpired in the late last decade, literature indicates that public organisations specifically LGAs have been one of the earliest adopters of IT [13]. This can be traced to the origins in the chronicles of IT [2, 42]. The focus of the primitive applications of IT was on the automation of internal backend operations [29], whereas in more recent time the Internet has offered opportunities for LGAs to transform their external interactivities with the citizens [20,67]. Substantial investments in e-Government have been inspired by the aforesaid drivers and others benefits such as greater citizen orientation, better efficiency, improved effectiveness [16] and reduced bureaucracy [27]. Gupta and Jana [31] accentuate that eGovernment is no longer seen as an option but a necessity for all countries aiming for better and efficient governance. Nevertheless, Heeks [32] argues that these promised benefits remained persistently elusive in most e-Government implementations. Many researchers have attributed these failures to strategic e.g. lack of a collaborative strategy framework [61], technical e.g. integration of e-Government systems [44, 45, 50] and human behavioural e.g. decision making aptitude [34] aspects of e-Government implementation. In the following, the authors discuss on the national and local e-Government strategy in the UK and to what extent have the LGAs been successful in accomplishing the objectives of the e-Government strategy.

\subsection{National and Local e-Government Strategy for Transformational of Services in the UK}

The UK central government has, in common with other developed nations, put substantial organisational resources into e-Government (at all levels i.e. at the national and local levels) over the past decade [16]. As aforesaid, e-Government can be seen as the strategic use of IT in public sector organisations to aid or replace administrative processes that have been part of UK government [59]. By the 1990s, the UK government bureaucracy was entirely reliant on a complex network of IS, with virtually no department or LGA 'technology free' (e.g. [33]). These IS received little public or political attention (except when they went wrong) until the rise of the Internet and policy makers starting to realise the potential of new web-based technologies [49]. In particular, the Internet offered a challenge to all public sector organisations, including LGAs, to modernise and achieve citizen-centred services - to integrate policies and programmes, to join-up service delivery across departments and LGAs, and to harness the potential of IT [53].

Having a retrospect on e-Government implementation and the local e-Government strategy in the UK, the normative literature contemplates that local e-Government has reached a stage of maturity in that mandates set by central government for local e-Government have been achieved e.g. at a cost of $£ 184$ per household, over a 7 year period from 2001$2008[35,36]$. LGAs according to the e-Government strategy are expected to deliver a total of $£ 1.2$ billion in accumulated efficiency savings by 2007-2008 through realising the benefits of e-Government.

\subsection{Information Technology Adoption in LGAs}

The transformation of LGAs through IT adoption has been central to the political programmes of the UK government [10]. The UK public sector has for many years advocated that IT has the potential to deliver its services more quickly and at a lower cost [11]. Therefore, the rapid development in technology is contributing to the growth of interest in the strategic use of IT as an effective tool in realising the benefits of e-enabling and supporting LGA transformation. Taking into consideration the underlying propositions allied to the e-Government strategy, LGAs have implemented several information technologies to support citizen services, improve the efficiency and effectiveness of their operational activities to reposition their services at regions closer to the citizens $[60,75]$. Despite several LGAs meeting the local e-Government objectives, prior IS research in context exhibits several difficulties impeding the IT-enabled organisational transformation in many LGAs such as including among others: (a) non-integrated nature of their IT infrastructure do not allow LGAs to deliver end-toend integrated services [44, 45, 50], (b) lack of a single approach for implementing IS and instead developing IS independently to provide specific business solutions [37], (c) inflexible IS security 
requirements further constraining integration [73], and (d) focusing on short term technical benefits and failing to achieve long term strategic goals for integrating IT infrastructures [40]. This has resulted in a wide range of different technologies and disparate IS with incapability to interoperate and eventually developing islands of information [37, 40, 50]. The inaccessibility of substantial data archives and business processes in the isolated IS within LGAs, is at the heart of the foremost pressing challenges facing the architects of today's IT infrastructures in transforming LGAs [37, 73].

Despite the growing interest in this area, in-depth enquiries into how LGAs overcome the several impediments in their way to manage IT-enabled transformations has remained relatively limited [22, 66]. A possible explanation for the scarcity of research interest is the pessimistic impression of LGAs as rigid, risk-averse and having insignificant desire for improvement [50, 57]. Regardless of the several unfavourable beliefs, recent years have witnessed a rush of the implementation of eGovernment to re-invent LGA services [73]. Themistocleous et al., [69] argues that e-Government platform should not been merely seen as a standalone system but as a solution that communicates with back office applications through an integrated infrastructure. As aforesaid, e-Government transformation is one of the biggest challenges within the IT-related sector from the perspective of scale and complexity, especially when it comes to adapting existing e-Government to new computing requirements based on the citizens' new service concept [17]. Integrated e-Government IS can efficiently automate the business processes of the public domain and increase citizens' satisfaction. However, to achieve such a solution, LGAs need to integrate their IT infrastructures to provide a common and shared view of their information and services $[10,44]$. The benefits of integration have not been attained due to incompatible IS, platforms, and high maintenance costs coupled with a lack of understanding of the true purpose, value and power of integrated IS [50]. LGAs have attempted to overcome their integration problems by interconnecting their disparate applications e.g. by point-to-point interconnection [75]. Nevertheless, integration is much more than merely interconnecting the disparate applications and the connectivity of applications was insufficient due to the fact that individual applications were not designed to interoperate with each other [70]. In the following, the authors highlight the main limitations with regards to the context of this research study.

\subsection{IT Adoption Limitations in LGAs}

Literature indicates that while LGAs have adopted several IT applications to overcome their integration issues and improve their e-Government IS operations and functions, the concerns of: (a) relying on external expertise; (b) providing quality citizen services; (c) automation; and (d) IT integration problems still persist. The authors argue that this may be attributed to several limitations including among others the lack of competence in LGAs top management in making appropriate strategic decisions for developing an organisationalwide IT infrastructure for e-Government. In a recent research conducted in the public sector, Irani et al., [34] observed that decision making with regard to eGovernment issues in the case study organisations was unsophisticated while the decisions were not made by top management but rather delegated to middle managers. This nature of top management resonates with the work of Bannister [7] who contends that decision making process in the public sector is often political and not always based upon economics. However, Irani et al., [34] contends that senior management commitment is critical to eGovernment success. Yildiz [76] also recently conducted an extensive research in the area of eGovernment with a technology enactment viewpoint. $\mathrm{He}$ highlighted several limitations to the eGovernment concept (e.g. related to its definition, maturity, significance) while also offering some topical suggestions to the political nature of eGovernment. One such suggestion relates to the policy decision-making processes in e-Government projects in a complex political environment.

Yildiz [76] highlights that the problem domains in which the LGAs operate are ill-structured. The top management attempt to solve inflexible and problematic problems that cut across LGAs and other government organisations vertically and horizontally [15]. Technical issues related to e-Government are no exception and several research studies are satiated with evidences [37, 41, 44]. Gil-Garcia and Pardo [28] argue that practitioners and managers within LGAs are not well-prepared to solve the technologyrelated problems as they cannot make use of most of the research in this area. Yildiz [76] asserts that this complicates the planning and decision-making processes in LGAs. Brown and Brudney [15] also support that such attitudinal perceptions of government decision makers also constrain these processes. However, a better investigation and understanding of the attitudinal and other behavioural determinants influencing the decision making process for IT adoption might help in making the complexity more manageable. Therefore, based on the aforesaid literature, the authors argue that successful decision making and selection of appropriate IT solutions rely heavily on the attitudes 
and behaviours of top management towards the adoption and integration of new technology into existing environments of LGAs. In the following, the authors discuss on the attitudinal and behavioural determinants influencing the decision making process at an individual level in organisations.

\section{Attitudinal and Behavioural Determinants Influencing the Decision Making Process: A Conceptual Perspective}

Literature indicates that the decision making process in an organisational context is often associated with the behaviour and attitude of individuals and groups and usually studied at three levels. For example (a) strategic decision making (e.g. that influences the whole organisation), (b) decision making by groups (e.g. that usually focuses on the dynamics of the decision process and this has an influence on the way decisions are made) and (c) decision making by individuals (e.g. which is the focus on this research) [63]. With regards to the strategic decision making process, Papadakis et al., [58] highlights that strategic decision-making has emerged as one of the most active areas of current management research that has greatly benefited from research traditions such as Behavioural Decision Theory (BDT). In the context of taking decisions on technology adoption, Au and Enderwick [6] report that the attitude and behaviour towards adoption is the cognitive process which depicts the prospect adopter's positive and negative affection while adopting IT. Technological adoption has been an important area for IS research and practice [25]. There are several well established theories that have been proposed to study and facilitate the understanding of determinants influencing the adoption of information technologies. These include the Technology Acceptance Model (TAM) [19], Theory of Planned Behaviour (TPB) [3], Decomposed Theory of Planned Behaviour (DTPB) [68], Innovation Diffusion Theory (IDT) [62], Information Technology Adoption Model (ITAM) [23], and Unified Theory of Acceptance and Use of Technology (UTAUT) [71].

While these theories focus on an individual's perceptions on adoption and use of a particular new invention or technology, the research in context is focused towards understanding the determinants influencing an individual's decision making on technology adoption and integration. Therefore this study draws from three research themes based on determinants influencing the decision making process in organisations. These determinants are associated with three different contexts such as (a) individual, (b) decision, and (c) organisational, that influences the decision making process [63]. The focus on this research study is to investigate the attitudinal and behavioural determinants influencing top management's decision making process for integration technologies adoption in LGAs. In this context, the authors take into consideration the individual determinant theme (Figure 1) and incorporate this in the way LGAs' top management make their decisions regarding technology adoption at individual level. Rollinson [63] argues that it is vital to comprehend and recognise that the nature of decision making is influenced by the surrounding context and, in return, the resulting decisions have an effect on the context. Ford and Richardson [26] support this argument and state that individual determinants have received by far the most research attention in the empirical literature. This category includes all those determinants that are uniquely associated with the individual decision maker. With this conception in mind, the authors move forward and investigate on a more comprehensive illustration of the determinants that may shape the nature of the decision making process for integration technologies adoption in local government authorities. As highlighted in the normative literature the government's plans to modernise LGAs consist of two components, to modernise decision making and to improve service delivery. Brooks [14] states that the modernising LGA IT project contains within itself the most significant pressures, thus by advocating new decision-making structures; the modernisers may expect improvements in the accountability of LGAs.

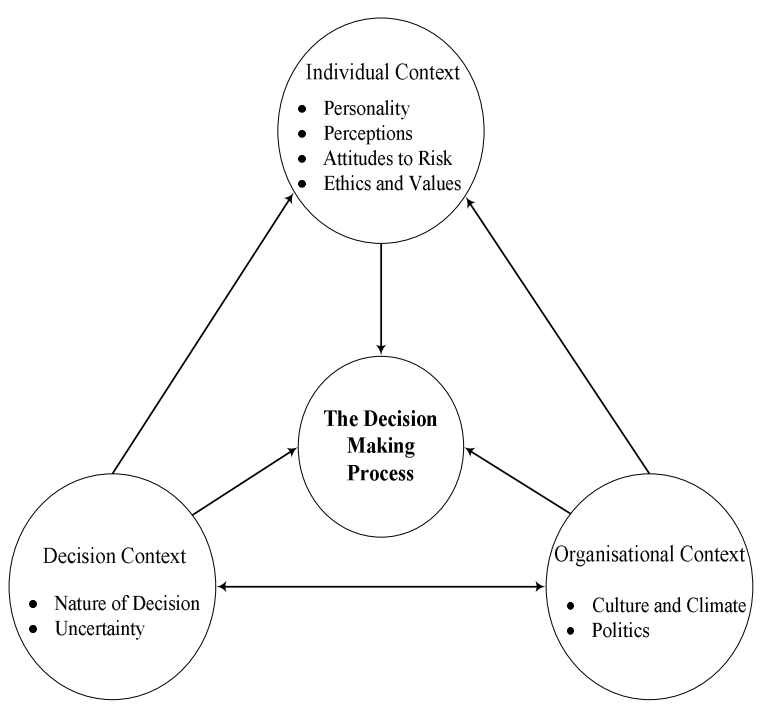

Figure 1: Determinants Influencing the Decision Making Process (Source: [63]) 
Individual differences can have profound influence on how people approach the matter of making decisions and, in this regard four differences can be significant [63]. These differences are four different determinants of the individual theme. Taking into consideration the individual theme of determinants influencing the decision making process, the authors commence the debate by describing each determinant of the individual theme.

\subsection{Personality}

By definition, no individual is similar to the other and there are several ways to distinguish between them with the most commonly used is differentiating through personality $[4,26,63]$. There are four different general determinants that can form personality determinant of people such as genetic (e.g. determinants that influence physical and mental characteristics of a person), social (e.g. determinants that influence personality that arise from interaction with other people), cultural (e.g. determinants such as wider social beliefs, values and motives that are absorbed by an individual and guide behaviour towards which is acceptable within a specific social context) and situational (e.g. such determinants that put the effect of a specific experience or situation on an individual's feelings and behaviour) determinants $[26,63]$. Personality can have an impact on a person's preferred behaviour in a particular decision context. For example, Rollinson [63] explains that highly manipulative people can view the decision situation as an opportunity to manipulate others for their own personal gain. Thus, they might have a tendency to keep decisions to themselves, or withhold vital information to maintain control over other people in the organisation. Depending on their status in the organisation, top management that has the highest authority can behave in one of two ways $[4,63]$. Several senior managers have a low tolerance to ambiguity and endorse the idea of a highly ordered environment, which can prompt them to rely on precedents and rules to guide decision making. If managers of such nature occupy high ranking positions, they may also view decision making as something that should not be shared with subordinates but as a prerogative of their rank. The above discussed literature provides sufficient justification for the authors to propose the following research issue for further investigation:

Research Issue 1 (RI-1): The authors consider personality as a determinant that may positively/negatively influence the decision making process for the adoption of integration technologies in local government authorities.

\subsection{Perceptions}

Rollinson [63] interprets perception determinant as an active mental process that involves the selection (e.g. the tendency to acknowledge some stimuli and ignore others), organisation (e.g. the organisation of stimulus information into meaningful patterns that form identifiable wholes), and finally, structuring and interpretation of information in order to make inferences and give meaning to the information. MacCrimmon [47] supports and highlights that perceptions can strongly influence the way top management view a problem and so they are likely to interact with personality determinants to shape preferred decision strategies. For instance, Rollinson [63] supports that if a person's prior experience has been confined to a restricted range of situations involving only bounded problems, he or she will probably have a tendency to see most new problems as similarly bounded. Beck and Kieser [9] argue here that while depending on the person's occupational history, he or she can develop a bias towards seeing all problems in a specific way and to seek solutions accordingly. Perception is an important way in which people differ as individuals and can influence they way they behave in organisations. Given this context, the authors propose the following research issue for further investigation:

Research Issue 2 (RI-2): The authors consider perception as a determinant that may positively/negatively influence the decision making process for adoption of integration technologies in local government authorities.

\subsection{Attitudes towards Risks}

For the discussion in this section, the authors initially take into consideration the definition of attitude. Allport [5] defines attitude as "a mental and neural state of readiness, organised through experience, exerting a directive or dynamic influence upon the individual's response to all objects and situations with which it is related". Rollinson [63] adds to this definition that attitude can be thought of as the combined effect of a belief and a value, which gives a feeling about a particular object and this in turn, forms a link between attitude and behaviour. The authors argue here that when it comes to top management making decision that may involve risk, such as in the case of e-Government initiatives [28], this can directly influence the attitudes of risk-averse managers and make them require higher rates of return before they invest on these initiatives. Bass [8] supports that people vary in their acceptance of risk and generally, individuals can be placed along a continuum, the extremes of which are risk-takers and 
risk-averters. MacCrimmon and Wehrung [48] report that based on their location on this continuum, people tend to displace characteristic patterns of behaviour in decision making. Regardless of these conceptions, Rollinson [63] argues that people's tolerance of risk can change over time. For example, the authors argue that repeated exposure to risky situations may lead to progressively lower perceptions of the riskiness of a situation and an increase in tolerance to risk. Given this context, the authors propose the following research issue for further investigation:

Research Issue 3 (RI-3): the attitude towards risk determinants may positively/negatively influence the decision making process for the adoption of integration technologies in local government authorities.

\subsection{Ethics and Values}

Ethics can be referred to as an individual's moral beliefs about what is right or wrong, or good and bad, and provides a guide to his or her behaviour [26,63]. A number of researchers have proposed a variety of theoretical models in the effort to explain and predict the process by which management makes ethical decisions and by taking into consideration its related values (e.g. [12, 39]). While any of these models might serve as a basis for undertaking empirical study of the ethics and values related to decision making process, there is little effort on testing this determinant in the context of integration technologies adoption in LGAs. Jones [39] highlights that ethical decision making is a decision that is both legal and morally acceptable to the larger part of the organisation. Rollinson [63] argues that ethical behaviour is not solely determined by individual predispositions, but usually is the result of an interaction between individual determinants and contextual variables. Since concern about ethics infuses a degree of ambiguity into a decision, and for most people vagueness can be unpleasant, this can have a huge impact on the decisions that are taken $[12,39,63]$. At one extreme, individuals attempt to guard their core values by either not making decision or behaving with extreme ethical enthusiasm. At the other extreme, they can endeavour to exclude their values by rationalising that anything goes so long as they put the good of the organisation before their own feelings [63]. Based on the aforementioned conceptions, the authors propose the following research issue for further investigation:

Research Issue 4 (RI-4): As all the evidences support the significance of 'ethics and values' determinant, thus it may also positively/negatively influence the decision making process for the adoption of integration technologies in local government authorities.

The literature reported in this section illustrates that the role of personality, perceptions, attitude towards risk, and ethics and values are considered to be highly important in the decision making process. As a result, the authors propose that when exploring the adoption of integration technologies in LGAs, these four determinants may provide a deeper understanding of the way top management take decisions while adopting integration technologies. In the following section, the authors present the research methodology used to test the research issues proposed in this section for further investigation.

\section{Research Methodology}

As this study attempts to explore and test the research issues set out above in a deep and meaningful manner, an interpretive, qualitative multiple case study approach was considered to be suitable [21,72]. Case studies were carried out in two large local government agencies which were identified through personal contacts in Local Government. For confidentiality reasons, the authors use the names LGA_A and LGA_Z to refer to both the case organisations. The authors contacted the Personal Assistant (PA) to the heads of the IT departments within these case organisations and arranged to meet at a scheduled time. The authors acquired written permission from the two LGAs before commencing the case studies in July 2008. Interviews that lasted between 1 and $2 \mathrm{hrs}$ constituted the main data source in the case organisations. Three top management level participants who are considered as decision makers in the integration technologies adoption process from each LGA_A and LGA_Z were interviewed using semi-structured interviews and the aid if an interview agenda [77]. Follow up interviews were then carried out to clarify any issues that were unclear. The interviews took place at interviewees' office in the local authority premises.

The authors also had the opportunity to perform unstructured interviews during lunch, coffee breaks and out of office hours. Using unstructured interviews some important data regarding the case studies were collected. The data analysis was done by transcribing the information onto a document and later analysing the document using a thematic analysis process. This involved encoding the qualitative information in order to identify particular themes that may have some relevance to the area of research. All of the interviews were tape recorded and transcripts prepared as soon as possible after each individual interview. Tape recordings supported 
the authors in collecting accurate data and interpreting them without time pressures. The interviewees selected for interviews included Head of ICT (HICT), Project Manager (PM), Senior Service Delivery Manager (SSDM) from LGA_A and Head of IT (HIT), Project Manager (PM) and Senior Web Manager (SWM) from LGA_B, all of whom have been directly involved in the integration technologies projects. Such stakeholders had an important role during the decision making process. Therefore, it was considered important to select a cross section of roles in the integration technologies projects to obtain the views of stakeholders at different levels in the case organisations. This supports better understanding of the adoption of integration technologies in an LGA context.

\section{A Multiple Empirical Case Study Analysis of the Attitudinal and Behavioural Determinants on the Adoption of Integration Technologies}

\subsection{Case Organisation - LGA_A}

LGA_A case organisation provides its services through various service areas including social and environmental services, property, housing, education, health etc. In the past, each department developed their own IT infrastructures. As a result, LGA_A consisted of numerous heterogeneous information systems that were based on a diversity of platforms, operating systems, data structures and computer languages. Most of these systems were legacy applications that still today run on mainframe environments. Since there was a lack of common IT infrastructure, and a lack of central coordination of IT, the majority of LGA_A departments adopted their own applications to support their business activities. These individual applications were not developed in a coordinated way but instead had evolved as a result of latest technological innovations. This has led to incompatible systems with integration problems. LGA_A has attempted to overcome this problem by integrating their systems.

These problems became an obstacle for them as they prevented LGA_A from implementing their business goals. For instance, LGA_A could not support its goal of closer collaboration and coordination of inter-organisational business processes due to the non-integrated nature of its applications. This held LGA_A back from achieving an integrated IT infrastructure and cost reductions. The limitations of IT infrastructures led top management in the IT department to take a decision to significantly advance in their service delivery by adopting a solution to integrate their IT infrastructure. LGA_A initiated a plan for developing a demonstration pilot project. The motivation behind this pilot project was to address the limitations of its existing systems, and to meet the targets set by the central government. On this basis the adoption of such integration architecture within LGA_A and other London boroughs will deliver measurable business benefit. The interviewees had their rational motivations behind supporting the decision for implementing an integration solution. For example, the HICT stated:

we had to improve our service delivery,
reduce costs and improve performance
management. As the technology
integration solutions that we
considered supported in developing
flexible working environments, such as
integrating systems in more flexible
ways and allowed to access and share
information, we decided to invest in an
integration solution ..."

As the decision was taken to invest in an integration technological solution for developing a demonstration pilot project, all the three interviewees were individually asked to comment on what were their specific attitudinal and behavioural determinants that influenced their decision making process for adopting an integration solution. The HICT reported:

“... I strongly advocate the use of technology for service improvement. However, the public sector has unfortunately been slow to take advantage of the benefits offered by modern ICT facilities available. Therefore, we have been lagging behind in terms of customer service, speed and efficiency in comparison to the private sector. I believe that we can not modernise local government without the use of technology ... I am not suggesting that we throw away existing technology, but we can attempt to utilize our legacy systems by integrating with new technology..."

The favourable attitude towards the adoption of integration technologies at LGA_A is further captured in the comments by SSDM. He stated that:

“... if we do not reengineer our processes, our local authority will be left behind as most of the councils that are higher up on the e-government league table have demonstrated that we 
need to utilize cost effective integration solutions and enterprise architectures that have emerged recently, such as Service Oriented Architecture (SOA) and Enterprise Service Bus (ESB) to reengineer and integrate business processes ..."

Similarly, the PM also supported the above views, when he stated:

"... we want to be seen as a leader in
e-government implementation. The
objective of this pilot project was to
demonstrate to LGA_A and to other
London boroughs that are investing in
a long-term programme of integration
between packaged systems and legacy
applications is necessary..."

\subsection{Case Organisation - LGA_Z}

LGA_Z provides a range of key public services, including among others education, social and environmental services, property, highways, planning and refuse collection. The staffing establishment is 6,000 , the annual revenue budget is $£ 200 \mathrm{~m}$ and the annual IT revenue budget is $£ 3.5 \mathrm{~m}$. LGA_Z currently serves approximately 120,000-130,000 citizens and public sector customers. LGA_Z receives approximately 1000 citizen queries via telephone, whereas, face-to-face contacts are approximately from 100-250 on daily basis. The queries and face-toface contacts are measured by the contact centre. The HIT inherited a number of disparate legacy IT systems. Prior to progressing towards e-Government service delivery, LGA_Z had over 220 IT/IS systems deployed throughout the organisation. These systems helped and supported all service delivery functions and operated on a range of over 25 heterogeneous computer platforms and operating systems. When the e-Government initiative was announced, very little funding was provided by central government to implement e-Government in Wales. Unlike other parts of England, where considerable funding was being offered for e-Government projects and related initiatives, LGA_Z was allocated much smaller funding. When considering integrating existing systems with e-Government IS, an initial options appraisal process was undertaken for each of the 220 incumbent systems that LGA Z has. This included a specific set of criteria, developed by the Chief Information Officer (CIO) and agreed by top management. The criteria was: (a) whether the existing system required upgrading to accommodate a new version, new features or future organisational and user needs; (b) considering ease of integration from one system to another; (c) whether lease or licensing agreements on IT/IS equipment on hardware and software was coming to an end; (d) user satisfaction with existing legacy system; (e) consideration of training needs for both internal and external (citizen) users; (f) user and service disruption; and (g) costs to integrate.

The above determinants were considered when determining the systems that would need to be integrated with e-Government IS. However, it was quite clear that the significant costs and resources required to implement EAI system made its adoption not viable and prohibitive. It was important that costs were limited to the budget set by LGA_Z for integrating IT/IS systems in an e-Government context. As a consequence, LGA_Z had to implement an e-Government solution within the small amount of funding available and focus on generating synergies with the existing technology resources. IT integration challenges with e-Government were significant and therefore successful planning represented a major task. To avoid huge costs, a traditional integration approach was undertaken. Given the importance and implications of this decision, the preparation of the IT and e-Government IS integration strategy was presented and agreed by the LGA_Z top management. This was then communicated throughout the organisation. Many of the systems previously implemented had been properly considered and evaluated in relation to the particular service delivery function. However, as legacy systems they were not easily integrated with eGovernment IS. For example the existing planning system was successful at processing and helping planning officers in determining planning applications. However, the system did not have Internet/website facilities. Therefore, LGA_Z determined whether any business elements overlapped and then determined how to integrate older technology with the new e-Government programme. LGA_Z hence, decided which legacy systems were to be integrated with the e-Government consolidation programme. The CIO stated that:

“... there was a need to be responsive and open to changes to give the best solution possible for the existing infrastructure...".

As the decision was taken to invest in a tradition integration approach for interconnecting their IS, even in this case all the three interviewees were individually asked to comment on what were the attitudinal and behavioural determinants that influenced their decisions for adopting a traditional integration approach. HIT reported that: 
“... we have limited budgets and funding restrictions as compared to central England and therefore, I have to ensure a thorough evaluation of the short and long term cost benefit analysis. To an extent I am working with my hands tied to my back and I have to take a risk averse attitude towards any investments that are difficult to justify to my superiors and stake holders...."

Interestingly, a similar view was held by the PM at LGA_Z. He commented that:

“... when our legacy systems are doing what we want from them, why should we change out systems and upset the balance of our IT infrastructure..."

The third interviewee, SWM stated that:

“... when we talk about new technology and changes to our existing IT infrastructure, we have to think about our IT staff and how any proposed changes will impact them. Getting used to new technology takes time and will involve a period of training and education. I can guarantee you that there will be resistance to any IT related change not only from the users, but also from the IT unit..."

\section{Discussion and Conclusions}

The adoption of integration technologies has been explored widely in previous research, but largely from an organizational and technical perspective covering issues such as cost, benefits and barriers. To the best of the authors' knowledge limited research exists that explored the human attitudinal and behavioural aspects of top management's decision making aptitude towards the adoption of integration technologies. This study set out to inquire further into this under-explored area of research. The existing literature on the influence of attitude and behaviour in decision making contexts, point to determinants such as personality, perception, attitude towards risks and ethics and values. These determinants are largely linked to the psychological makeup of an individual $[4 ; 26 ; 63]$.

The empirical evidence presented in the previous section points to two different schools of thought with regards to the aforesaid determinants with regards to the adoption of integration technologies. For example, interestingly, individuals in LGA_A based in central England showed a more 'positive' attitude towards technology that resulted in favourable behaviour in accepting change. This can be attributed to the availability of sufficient funding from central government which enforced less pressure on the decision makers in LGA_A. On the contrary, the opposite was true in LGA_ $\bar{Z}$ where the decision makers were forced to take a risk averse approach resulting in a more 'negative' attitude and behaviour towards change.

In terms of implications to theory, this research synthesized existing literature to offer four different research issues that encapsulates attitudinal and behavioural aspects of decision making in an organizational context. These determinants were explored in a practical setting in the context of two local government authorities that were engaged in technology integration projects relating to egovernment implementation. The empirical results offer different doctrines; positive and negative attitude towards the adoption of integration technologies. They also show that the decision makers' individual attitude towards technology and change play a major part in the outcome of technology integration projects. The authors propose that these attitudes may be positively influenced when LGAs collaborate with private sector organisations for technology integration projects (e.g. by enlisting the help of expert consultants LGA IT managers and decision makers will be exposed to latest technology integration solutions and their associated benefits). Although this research study is based on two case studies, the beneficiaries (e.g. practitioners, researchers) can take this as a starting point to developing an understanding towards the attitudinal and behavioural determinants relating to the decision making for the adoption of integration technologies. The authors assert that with more empirical research, better harmonisation of theory and practice can be achieved in this relatively underexplored area of research. Future research can consider survey based studies to evaluate and quantitatively validate the impact of the research issues identified in this paper across a wider range of LGAs.

\section{References}

[1] Accenture. "Leadership in Customer Service: New Expectations, New Experiences", 2005, http://www.accenture.com/

[2] Agar, J. "The Government Machine: A Revolutionary History of the Computer", The MIT Press, Cambridge, Massachusetts, 2003.

[3] Ajzen, I. "The theory of planned behaviour", Organizational Behaviour and Human Decision Processes, 1991, 50, pp. 179-211. 
[4] Ajzen, I. "Attitudes, Personality, and Behaviour", Chicago, IL: Dorsey Press, 1988.

[5] Allport, G. W. "Attitudes in the history of social psychology", In G Lindzey and A Aronson (eds), Handbook of Social Psychology, 1, Reading, MA: AddisonWesley, 1954.

[6] Au, A. K. and Enderwick, P. "A Cognitive Model on Attitudes towards Technology Adoption", Journal of Managerial Psychology, 2000, 15(4), pp. 266-282.

[7] Bannister, F. "Dismantling the silos: extracting new value from IT investments in public administration", Information Systems Journal, 2001, 11(1), pp. 65-84.

[8] Bass, B. M. "Organisational Decision Making", Homewood, IL: Irwin, 1983.

[9] Beck, N. and Kieser, A. "The complexity of rule systems, experience and organisational learning", Organisational Studies, 2003, 24(5), 471-481.

[10] Beynon-Davies, P. "Constructing Electronic Government: The Case of the UK Inland Revenue", International Journal of Information Management, 2005, 25(1), pp. 3-20.

[11] Beynon-Davies, P. and Williams, M. D. "Evaluating Electronic Local Government in the UK", Journal of Information Technology, 2003, 18, pp. 137-149.

[12] Bommer, M. C., Gratto, J. G. and Tuttle, M. "A Behavioural Model of Ethical and Unethical Decision Making", Journal of Business Ethics, 1987, 6, pp. 265-280. [13] Bozeman, B. and Bretschneider, S. "Public management information systems: theory and prescription", Public Administration Review, 1986, 46(6), pp. 475-487.

[14] Brooks, J. "Labour's Modernization of Local Government", Public Administration, 2000, 78(3), pp.593612.

[15] Brown, M. M. and Brudney, J. L. "Learning organizations in the public sector? A study of police agencies employing information and technology to advance knowledge", Public Administration Review, 2003, 63(1), pp. 30-43.

[16] Chan, C. M. L. and Pan, S. L. "User Engagement in eGovernment systems implementation: A comparative case study of two Singaporean e-government initiatives", Journal of Strategic Information Systems, 2008, 17(2), pp. 124-139.

[17] Cheng-Yi, Wu. R. "Enterprise Integration in eGovernment", Transforming Government: People, Process and Policy, 2007, 1(1), pp. 89-99.

[18] Choudrie, J., Weerakkody, V. and Jones, S. "Realising e-Government in the UK: rural and urban challenges", Journal of Enterprise Information Management, 2005, 18(5), pp. 568-585.

[19] Davis, F. D. "Perceived usefulness, perceived ease of use, and user acceptance of information technology", MIS Quarterly, 1989, 13(3), pp. 319-340.

[20] Davison, R. M., Wagner, C. and Ma, L. C. K. "From Government to e-Government: A Transition Model", Information Technology \& People, 2005,18(3),pp.280-299.

[21] Denzin, N. Y. K. and Lincoln, Y. "Handbook of Qualitative Research", SAGE Publications, London, UK, 1994.

[22] Dhillon, G. S., Weerakkody, V. and Dwivedi, Y.K. "Realising transformational stage e-government: a UK local authority perspective", Electronic Government, an International Journal, 2008, 5(2), pp. 162-180.
[23] Dixon, D. R. "The behavioural side of information technology", International Journal of Medical Informatics, 1999, 56(1-3), pp. 117-123.

[24] Eyob, E. "E-Government: breaking the frontiers of inefficiency in the public sector", Electronic Government, 2004, 1(1), pp. 107-114.

[25] Fichman, R. "Information Technology Diffusion A Review of Empirical Research", Proceedings of the Thirteenth International Conference on Information Systems, 1992, pp. 195-206.

[26] Ford, R. C. and Richardson, W. D. "Ethical Decision Making: A Review of the Empirical Literature", Journal of Business Ethics, 1994, 13, pp. 205-221.

[27] Fountain, J. "Building the Virtual State: Information Technology and Institutional Change", Brookings Institution, Washington, DC, 2001.

[28] Gil-Garcia, J. R. and Pardo, T. A. "E-government success factors: Mapping practical tools to theoretical foundations", Government Information Quarterly, 2005, 22 , pp. 187-216.

[29] Gronlund, A. and Horan, T. A. "Introducing e-Gov: History, Definitions, and Issues", Communications of the AIS, 2004, 15(39), pp. 713-729.

[30] Gupta, B., Dasgupta, S. and Gupta, A. "Adoption of ICT in a government organisation in a developing country: An empirical study", Journal of Strategic Information Systems, 2008, 17(2), pp. 140-154.

[31] Gupta, M. P. and Jana, D. "E-government Evaluation: A Framework and case study", Government Information Quarterly, 2003, 20, pp. 365-387.

[32] Heeks, R. "Implementing and Managing eGovernment: An International Text", Sage Publication, London, England, 2006.

[33] Hudson, J. "Digitising the structures of Government: The UK's Information Age Government Agenda", Policy \& Politics, 2001, 30(4), 515-531.

[34] Irani, Z., Love, P. E. D. and Jones, S. "Learning lessons from evaluating e-Government: Reflective case experiences that support transformational government", Journal of Strategic Information Systems, 2008, 17(2), pp. $155-164$.

[35] Irani, Z., Sahraoui, S., Ozkan, S., Ghoneim, A. and Elliman, T. "T-Government for Benefit Realisation", Proceedings of European and Mediterranean Conference on Information Systems, Spain, 2007, pp. 1-11.

[36] Irani, Z., Elliman, T. and Jackson, P. "Electronic transformation of government in the UK", European Journal of Information Systems, 2007, 16(3), pp. 327-335.

[37] Janssen, M. and Cresswell, A. "An Enterprise Application Integration Methodology for E-Government", Journal of Enterprise Information Management, 2005, 18(5), pp. 531-547.

[38] Jones, S., Irani, Z. and Sharif, A. "E-Government Evaluation: Reflections of Three Organisational Case Studies", Proceedings of the $40^{\text {th }}$ Hawaii International Conference on System Sciences, Waikoloa, Big Island, HI, USA, 2007, pp. 1-8.

[39] Jones, T. M. "Ethical Decision Making by Individuals in Organizations: An Issue-contingent Model", Academy of Management Review, 1991, 16(2), pp. 366-395.

[40] Kamal, M. M., Themistocleous, M. and Morabito, V. "Justifying the Decisions for EAI Adoption in LGAs: A Validated Proposition of Factors, Adoption Lifecycle Phases, Mapping and Prioritisation of Factors", 
Proceedings of the $42^{\text {nd }}$ Hawaii International Conference on System Sciences, Hilton, Waikoloa Village Resort, Waikoloa, Big Island, Hawaii, 2009.

[41] Kamal, M. M., Themistocleous, M. and Elliman, T. "Extending IT Infrastructures in LGAs through EAI", Proceedings of the $14^{\text {th }}$ Americas Conference on Information Systems - AMCIS'08, Toronto, Canada, 2008.

[42] Kamal, M. M. "Investigating Enterprise Application Integration Adoption in the Local Government Authorities", PhD Thesis, Department of Information Systems and Computing, Brunel University, UK, 2008.

[43] Kolsaker, A. and Lee-Kelley, L. "G2C e-Government: modernisation of transformation?", Electronic Government, 2007, 4(1), pp. 68-75.

[44] Lam, W. "Investigating Success Factors in Enterprise Application Integration: A Case Driven Analysis", European Journal of Information Systems, 2005, 14(2), pp. 175-187.

[45] Lam, W. "Barriers to E-Government Integration", Journal of Enterprise Information Management, 2005, 18(5), pp. 511-530.

[46] Lee, S. M., Tan, X. and Trimi, S. "Current Practices of leading E-government countries", Communications of the ACM, 2005, 48(10), pp. 99-104.

[47] MacCrimmon, K. R. "Managerial Decision Making", In JW McGuire (ed.), Contemporary Management, Englewood Cliffs, NJ: Prentice Hall, 1974.

[48] MacCrimmon, K. R. and Wehrung, D. "Taking Risks", New York: Free Press, 1986.

[49] Margetts, H. "E-Government in Britain - A Decade On”, Parliamentary Affairs, 2006, 59(2), pp. 250-265.

[50] McIvor, R., McHugh, M. and Cadden, C. "Internet Technologies Supporting Transparency in the Public Sector", The International Journal of Public Sector Management, 2002, 15(3), pp. 170-187.

[51] Metaxiotis, K. and Psarras, J. "E-government: new concept, big challenge, success stories", Electronic Government, 2004, 1(2), pp. 141-151.

[52] National Assembly for Wales, "Guidance to Local Authorities on Implementing e-Government Statements", National Assembly for Wales, Cardiff, UK, 2002.

[53] Newman, J., Raine, J. and Skelcher, C. "Transforming local government: innovation \& modernisation", Public Money \& Management, 2001, 61-68.

[54] Office of the Deputy Prime Minister. "The National Strategy for Local e-Government", http://www.localegov.gov.uk/, 2002.

[55] Office of the Deputy Prime Minister. "One year on The National Strategy for Local E-Government", http://www.localegov.gov.uk/images/National\%20Strategy \%20-\%201\%20year\%20on 248.pdf, 2003.

[56] Office of the Deputy Prime Minister. "Two Years On: Realising the Benefits from our Investment in EGovernment", The National Strategy for Local EGovernment, http://www.localegov.gov.uk/, 2005.

[57] Ongaro, E. "Process management in the public sector: the experience of one-stop shops in Italy", International Journal of Public Sector Management, 2004,17(1), 81-107. [58] Papadakis, V. M., Lioukas, S. and Chambers, D. "Strategic Decision-Making Processes: The Role of Management and Context", Strategic Management Journal, 1998, 19, pp. 115-147.

[59] Phang, C. W., Kankanhalli, A. and Ang, C. "Investigating organisational learning in eGovernment projects: A multi-theoretic approach", The Journal of Strategic Information Systems, 2008, 17(2), pp. 99-123.

[60] Reddick, C. G. "Factors that Explain the Perceived Effectiveness of E-Government: A Survey of United States City Government Information Technology Directors", International Journal of Electronic Government Research, 2009, 5(2), pp. 1-15.

[61] Reffat, R. "Developing a Successful E-Government", Working Paper, School of Architecture, Design Science and Planning, University of Sydney, Australia, 2003.

[62] Rogers, E. "Diffusion of Innovations", 4th ed., The Free Press, New York, 1995.

[63] Rollinson, D. "Organisational Behaviour and Analysis: An Integrated Approach", $4^{\text {th }}$ ed., FT Prentice Hall, 2008.

[64] Silcock, R. "What is e-government?", Parliamentary Affairs, 2001, 54, pp. 88-91.

[65] SOCITM. "Local Government Transformation and the Council Website", SOCITM, UK, 2006.

[66] Tan, C., Pan, S. and Lim, E. "Managing stakeholder interests in e-government implementation: Lessons learned from a Singapore e-government project", Journal of Global Information Management, 2005, 13(1), pp. 31-53.

[67] Tan, C. W. and Pan, S. L. "Managing eTransformation in the Public Sector: An e-Government Study of the Inland Revenue Authority of Singapore (IRAS)", European Journal of Information Systems, 2003, 12(4), pp. 269-281.

[68] Taylor, S. and Todd, P. A. "Understanding Information Technology Usage: A Test of Competing Models", Information Systems Research, 1995, 6(2), pp. 144-176.

[69] Themistocleous, M., Irani, Z. and Love, P. E. D. "Developing E-Government Integrated Infrastructures: A Case Study", Proceedings of the $38^{\text {th }}$ Annual Hawaii International Conference on System Sciences, Big Island, Hawaii, 2005, pp. 1-10.

[70] Themistocleous, M. "Justifying the decisions for EAI implementations: A validated proposition of influential factors", Journal of Enterprise Information Management, 2004, 17(2), pp. 85-104.

[71] Venkatesh, V., Morris, M. G., Davis, G. B. and Davis, F. D. "User acceptance of information technology: toward a unified view", MIS Quarterly, 2003, 27(3), pp. 425-478.

[72] Walsham, G. "Interpreting Information Systems in Organisation", Wiley, Chichester, UK, 1993.

[73] Weerakkody, V. and Dhillon, G. "Moving from EGovernment to T-Government: A Study of Process Reengineering Challenges in a UK Local Authority Context", International Journal of Electronic Government Research, 2008, 4(4), pp. 1-16.

[74] Weerakkody, V., Janssen, M. and Hjort-Madsen, K. "Realising Integrated E-Government Services: A European Perspective", Journal of Cases in Electronic Commerce, 2007, 3(2), pp. 14-38.

[75] Wimmer, M. A. "A European perspective towards online one-stop government: the e-Government project", Electronic Commerce Research and Applications, 2004, 1(1), pp. 92-103.

[76] Yildiz, M. "E-government research: reviewing the literature, limitations, and ways forward", Government Information Quarterly, 2007, 24, pp. 646-665.

[77] Yin, R. K. "Case Study Research Design and Methods", Sage, London, 1994. 